\title{
Voluntary medical adult male circumcision for HIV prevention in South Africa: The tensions between medicalised modernity and traditional practices
}

\begin{abstract}
While a staggered rollout of voluntary medical adult male circumcision (VMAMC) for HIV prevention has been initiated, traditional male circumcision (TMC) and noncircumcision are important signifiers of cultural identity and masculinity in South Africa. As part of a larger study, repeat semi-structured interviews with 30 adult men from Alexandra Township were conducted. A Straussian grounded theory approach was utilised to identify and unpack the theoretical categories that underpin the tension between tradition, modernity, and medicine within the context of VMAMC and HIV prevention. This tension is made possible by a necessity to maintain and uphold traditional practices that denote the cultural meanings of masculinity and adulthood with TMC or non-circumcision, while also considering the state-promoted uptake of novel prevention efforts given the ongoing concern of HIV prevalence in South Africa. The ways in which this tension is negotiated has bearing on public responses to VMAMC for HIV prevention and the uptake thereof. This study highlights the complexity of seemingly "simple" solutions to HIV prevention interventions through once-off body directed strategies to underscore the importance of critical public health psychology to the advancement and implementation of such interventions in South Africa.
\end{abstract}

\section{Introduction}

Research has indicated that by "circumcising $80 \%$ of all uncircumcised adult men in the countries with high HIV
Lynlee

Howard-Payne

Department of Psychology

School of Human \&

Community Development

University of the

Witwatersrand Joahannesburg lynlee.howard-payne@ wits.ac.za

\section{Keywords}

grounded theory, HIV prevention, modernity, traditional male circumcision (TMC), voluntary medical adult male circumcision (VMAMC) 
prevalence and low prevalence of male circumcision by 2015 would avert one in five new HIV infections by 2025" (UNAIDS, 2013: 18). Thus, in order to meet the target of medically circumcising 20 million men by 2015, South Africa (along with 15 other African countries) up scaled the implementation of HIV prophylactic VMAMC since 2007. However, the uptake of VMAMC has varied significantly between these countries, for example, by the end of 2012, South Africa had only reached $20 \%$ of its target for the number of men set to undergo VMAMC while Kenya had reached 63\% of its 2015 target (UNAIDS, 2013). One of the reasons for this difference in VMAMC uptake may be related to the tension that exists in South Africa between tradition and medicine as well as the meanings assigned to these different practices as they relate to male circumcision. In urbanised Johannesburg, where men seem to concurrently perpetuate and discard characteristics and performances of hegemonic masculinity, there is a space for a tension between tradition and medical modernity. As such, this paper addresses this tension by firstly unpacking VMAMC as part of an inclusive HIV prevention strategy in South Africa. This is then considered against the backdrop of TMC practices as performed within traditional male initiation (TMI) among Xhosa, Ndebele, Tsonga, Venda, Tswana, and Northern Sotho men in South Africa. The methods used to collect and analyse repeat interview data, which explored this tension, are offered prior to presenting an integrated discussion of the analysed data. These findings show that the reach of biomedicine as a master discourse in modernity is often tensioned by other discursive contexts that draw on cultural understandings and politics of TMC with regards to the adoption of particular HIV prevention strategies, such as VMAMC. This paper problematises medical modernity whereby traditional practices (such as male circumcision) have come under medical influence, supervision and control in the context of HIV prevention. It shows how participants negotiate their position on VMAMC in light of the medicalisation process and their understanding of TMC. This negotiation needs to be considered by those who may uncritically promote VMAMC as an HIV intervention in South Africa.

\section{VMAMC for HIV prevention}

The epidemiology of HIV in Sub-Saharan Africa reveals that $90 \%$ of adults may acquire HIV via penetrative peno-vaginal sexual intercourse (UNAIDS, 2013). This finding has directed public health researchers' focus towards investigating the factors that may impact on the transmission of HIV for males by concentrating on the anatomical structure of the penis as being one possible modifiable vector of HIV infection in men. Biological studies have shown that the delicate tissue of the foreskin is vulnerable to microscopic lesions, which increases the risk of contracting HIV (Silverman, 2004). The foreskin also houses specialised Langerhans cells, which HIV and other pathogens can readily attach to (Halperin \& Bailey, 1999; El-Hout \& Khauli, 2007; Bhattacharjee, 2008; Auvert et al, 2013). Studies have shown that, by removing the foreskin, a man's risk of contracting HIV through peno-vaginal penetrative sexual intercourse may be reduced by approximately

PINS [Psychology in Society] 52 • 2016|20 
$60 \%$ (Bailey, Plummer \& Moses, 2001; Siegfried et al, 2003; Auvert et al, 2005; Williams et al, 2006; Bonner, 2007; El-Hout \& Khauli, 2007; Schoen, 2007).

This finding, however; is not entirely conclusive (De Vincenzi \& Mertens, 1994; Van Howe, 1999; Boyle \& Hill, 2011; Van Howe \& Storms, 2011). Some report that the claim that VMAMC prevents HIV can only be made for men who engage in particularly high-risk sexual practices and not men in the general global population (Green et al, 2008; Morris et al, 2012). Others have also indicated that such claims are based on flawed research methodologies that attribute causality to human anatomy rather than the complex factors that guide sexual behaviour for vulnerability to HIV infection (Van Howe et al, 2000; Dowsett \& Couch, 2007).

Until such time as methodologically sound, randomised controlled trials can undeniably confirm the exact mechanisms at play for reducing HIV transmission for the circumcised male, VMAMC may be debated as a viable, ethical, and acceptable method of HIV prevention. Such debates may influence the way in which the public makes meaning of VMAMC as either being a culturally-suitable programme that is considerate of the numerous socio-cultural factors implied by this HIV prevention strategy or one that stands in opposition to TMC as practiced within TMI in South Africa.

\section{Community acceptability of circumcision and willingness to circumcise}

Interestingly enough, research has shown that in African countries where male circumcision is not regularly or traditionally performed, there is a relatively high level of acceptance regarding VMAMC as a public health intervention to combat the spread of HIV (Stine, 2008). A meta-analysis of the acceptability of VMAMC conducted by Westercamp and Bailey (2007) showed that the median proportion of uncircumcised men willing to undergo VMAMC was $65 \%$ (range $29-87 \%$ ), while approximately $70 \%$ of women would prefer VMAMC for their partners or their sons and the same percentage of men would prefer VMAMC for themselves or their sons.

Countries such as Zambia have helped raise awareness of the procedure's potential health benefits via mass media advertising and hospital newsletters. As a result of this media attention there has been an overwhelming response, with men travelling great distances from rural areas to the cities to undergo VMAMC (Stine, 2008). In Botswana, Kenya, South Africa and Swaziland, when men or women were asked about VMAMC for their sons, more adults would agree to the procedure for their child than for their spouses or themselves. Approximately $75 \%$ of parents would seek VMAMC for their son if it was safe, affordable and shown to be undeniably protective against HIV and sexually transmitted infections (STIs) (Westercamp \& Bailey, 2007). 
The meta-analysis by Westercamp and Bailey (2007) showed that overall, 65\% of uncircumcised men were willing to undergo VMAMC for hygiene reasons and to reduce their risk of HIV and STIs. In rural areas, 51\% of men were willing to undergo VMAMC compared to $77 \%$ of men in urban areas. While such studies offer valuable indicators regarding the uptake of VMAMC as a method of HIV prevention, these acceptability studies do not offer an account of why there may be a discrepancy in such decision endpoints. That is to say, such studies are unable to detail the reasons as to why a man would undergo HIV-preventative VMAMC or not, nor do they account for the fact that there seems to be high acceptability of VMAMC in South Africa but relatively low uptake thereof.

Despite the concerns and challenges to the implementation of VMAMC, the South African government continues to pursue this initiative, in light of its prophylactic evidence, as a method of HIV prevention. However, the success of any HIV prevention strategy depends on the social context in which it is implemented, as it has to be considered credible, culturally relevant, and practical by all the intervention stakeholders involved. For this reason, should VMAMC be considered a worthy intervention for implementation, the value and significance of VMAMC needs to be considered beyond its value as a method of medicalised male body modification in an attempt to reduce the spread of HIV within the South African setting. This involves the contemplation of TMC as a rite of passage in South Africa.

\section{A traditional ritual and rite of passage}

In South Africa, $25 \%$ of males are circumcised with considerable variation across its nine provinces (Department of Health, 2013). These variations in the practice (see table 1) attest to the fact that circumcision has different geographical patterning, which often proxies for other types of differences such as language, culture and religion (Moses, Bailey \& Ronald, 1998). 
Table 1 - Percentage of traditionally circumcised males per province in South Africa

\begin{tabular}{|l|l|}
\hline South African Province & Percentage of circumcised males \\
\hline Free State & 21 \\
\hline Western Cape & 21 \\
\hline Limpopo & 48 \\
\hline Eastern Cape & 55 \\
\hline Mpumalanga & 25 \\
\hline Northern Cape & 8 \\
\hline North West & 20 \\
\hline KwaZulu-Natal & 8 \\
\hline Gauteng & 18 \\
\hline
\end{tabular}

Sourced from: Department of Health (2013)

TMC represents a context-bound, transitional, sacrificial practice of cutting or marking the penis to symbolise the shift from childhood to adulthood (Mbito \& Malia, 2009; Peltzer \& Kanta, 2009). Xhosa people view the foreskin as a "cloak" that veils the penis and when a boy comes of age (between the ages of 17 and 20 years), this "cloak" is removed, representing his ownership of powerful adult masculinity (Boddy, 1989; Crowley \& Kesner, 1990). This rite, mandated by tradition and culture, sees TMC and TMI as a necessary practice that shifts of a boy into adulthood (Howard-Payne \& Bowman, 2016). Although TMC and TMI practices are not immutable across time and context, it is typically a communal practice performed in mountainous rural areas whereby the intact initiate would be joined by 20 other young men to be circumcised by a traditional healer as a celebration of his entry into manhood (Mark et al., 2012; Howard-Payne \& Bowman, 2016).

Historically the practice of TMC in many African cultures was challenging for Christian missionaries, where the rite, in many ways, represented the "primitive" past (Aggleton, 2007). At the same time, however; male circumcision carried a biblical endorsement from both Abraham and Jesus Christ (Silverman, 2004; Massry, 2011). After World War II, health orderlies introduced medical male circumcision (MMC) to Papua New Guinea (Silverman, 2004). As a result, circumcision became associated locally with the medical hygiene practices of modern Europe. The rite, which for the missionaries was related to Christ's crucifixion and Christian purification, slowly became integrated into TMI as rite of passage into manhood by the 1950s and 1960s (Silverman, 2004). This case highlights that male circumcision can indeed serve various functions (biomedical / hygiene foci, religious and cultural rites) at the same 
time, implying that its use as an HIV preventative medical application in a South African setting could be understood alongside its other context-bound meanings, including TMC.

Theoretical accounts of TMC share health and lines of patriarchy as common underlying determinants. As such, TMC appears to mark masculinity and play a role in the assumed hygiene of the circumcised group. These factors have been extensively studied in circumcising populations, but aside from historical and descriptive accounts, insights into the way these factors may feature in individual meaning-making of VMAMC in the context of HIV prevention are limited. Also, very little is known about why or how such apparently widespread belief-based practices anchor certain forms of patriarchy and hygiene in some groups, but not others. However, these anchors are not without their tensions, particularly in consideration of modernity and urbanisation.

\section{Modernity and urbanisation}

Considering the history of Johannesburg and its development into a cosmopolitan city, where most of its inhabitants migrated from rural areas to its centre in search of employment and resources, it is not surprising that a number of its residents maintain ties with their rural "homelands". It may be difficult to maintain traditional values and customs when living within a large metropolitan city like Johannesburg where communities are less homogenous than in more rural areas of South Africa. It could be argued that rural communities uphold collectivistic cultural ideologies while urban societies are more individualistic (Babones \& Babcicky, 2010; Nafstad et al, 2013). This is particularly relevant in consideration of VMAMC and TMC practices as a reflection of masculinity and patriarchy. These different cultural perspectives mean that individuals who have moved to urbanised locations can simultaneously hold seemingly contradictory positions regarding masculinity as being understood within traditional constructions of hegemony as well as "modern" forms of manhood.

In Johannesburg, people are confronted with social interactions and environments that are vastly different to those in their "homelands", and these urban experiences require individuals to be flexible in their responses to each in order to be considered socially "competent" (Tierney, 2014). That is to say that young men may adhere to a code of masculine conduct when they visit their rural homelands that is remarkably different to their way of life in the city where they reside. Navigating these different rural and urban masculine identities is a challenge as individuals are often compelled to adapt their individual meaning-making strategies to the context in which they are located at particular moments. 
For example, an individual may reject the traditional norms in his private life (to embrace modernity and urbanised performances of masculinity) while adopting such norms as part of his public life (Faist, 2000; Vaughan \& Arbaci, 2011; Ward, 2013). Thus, young men may simultaneously support and reject the inclusion of VMAMC as part of a comprehensive HIV prevention intervention, given that they personally wish to participate in the containment of the pandemic in South Africa through the uptake of VMAMC while also wishing to preserve the practice and meanings of TMC as part of TMI rituals.

The consideration of modernity and urbanisation highlights that the male body cannot be reduced to any sort of biological essence since foreskins are facts of personal and collective significance, where (depending on one's location in South Africa) the foreskin has been made culturally or biologically significant. Rather, it is an object of contestation and cultural debate, particularly where modern medicine is involved.

\section{Tensions and medical modernity}

For the purposes of this paper, medicalised modernity is defined as the modernisation or the gradual progression of a society from "pre-modern" to "traditional" and finally a "modern" state, whereby medical science has played a key role in this social development. Although this definition may appear to locate medicalised modernity as a linear structure, it does not preclude the theoretical and practical understanding of a developmental condition that occurs in a non-linear fashion. Thus the increasingly feature role that medicine seems to play in modern, urbanised societies was a critical phenomenon for investigation as it underpins the tensions between tradition and medicine in considering HIV-prophylactic VMAMC meaning-making, as men in South Africa regard the male body as a site for disease prevention via VMAMC as well as the vehicle through which adult masculinity is attained via TMC.

\section{Methods}

\section{Participants}

Participants who reside or work in Alexandra Informal Settlement, Johannesburg were recruited to participate in this study. This site was chosen for sampling as it is located within Gauteng, which has a HIV prevalence of $11 \%$ and also represents the national prevalence of HIV (UNAIDS/WHO, 2013). Furthermore, research has shown that adult men from this population embody varied urban masculinities that occupy spaces of plurality whereby masculine identities simultaneously eliminate and allow traditional hegemonic ideals of patriarchy (Langa, 2010). This space was of particular interest to the researchers as it represented the tension between tradition and medicine as it relates to the meanings of HIV prophylactic VMAMC and TMC. Snowball sampling strategies resulted in a final sample of 30 adult men (aged 18-64) nine of whom were from groups 
that practiced African TMC, one who practiced Jewish religious male circumcision, and 20 of whom who did not practice any form of traditional or religious circumcision. The participants were asked to indicate their home language, which was relied upon as a proxy for culture and TMC practices and thus had implications for the coding and analysis of data. This was critical for consideration in the grounded theory of individual meaning-making of HIV prophylactic VMAMC since such meaning was found to be made in relation to meanings of TMC practices. For a detailed account of recruitment and sampling procedures see Howard-Payne (2015).

\section{Data collection: Instruments and procedures}

As advocated by Charmaz (2014) the author relied upon repeat semi-structured interviews to gather data regarding VMAMC meaning-making. The interview schedule included general questions regarding TMC, VMAMC, and HIV in South Africa. Specific questions, as well as follow-up probing questions, relating to the tension between tradition and medicine included: "How do you think that different cultural and / or religious groups in South Africa will react to this possible HIV prevention intervention?", and "Which is more important, maintaining traditional practices or preventing HIV infection?". The necessary ethical clearance for this study was obtained prior to recruitment of participants. Fieldworkers (two multilingual black males) were employed in order to recruit and interview participants in the participants' preferred language. All of the interviews were conducted in English, except one that was conducted in isizulu, which was then translated and transcribed into English by the fieldworker. For further details regarding the data collection procedure see Howard-Payne (2015).

\section{Data analysis}

A Straussian grounded theory approach underpinned the data collection, coding, and analysis of the data. Howard-Payne (2016) addresses the exact procedures involved in this research method whereby formal and informal analyses were used to reveal the theoretical categories that underpinned the tension between medical modernity and tradition (within the context of HIV preventative VMAMC). Open, axial, and selective coding were used concurrently prior to utilising a conditional matrix to complement our understanding of the unique South African context and VMAMC for HIV prevention where tradition and medical modernity (through urbanisation and modernisation) are tensioned against each other. The categories that underpin this tension are presented and interpreted in the following section.

\section{Findings and discussion}

The theoretical frameworks that have attempted to account for the various demographical and epistemological shifts that accompany modernity are vast, but essentially consider that "traditional" societies, typically with the aid of more urbanised and industrialised 
counties, have the capacity to (over time) modernise their social and cultural structures (Schifirneţ, 2012). Participants referred to this as they alluded to the tensions that exist between rural and urbanised accounts of masculinity, HIV prevention, and medicine. Participants reflected on this tension as they indicated that they, as individuals, had the ability to enhance themselves and alter their society, primarily by critically reviewing their understanding of science, technology, economics, as well as their religious and cultural beliefs.

As participants considered the relevance of TMC and HIV prophylactic VMAMC to them personally, as well as their communities and the broader society, modernity emerged as a salient issue that was indirectly referred to by each participant as they reflected upon the tensions that exist between the meanings of these two practices. There was either a general longing for what P2 (single, isiZulu-speaking, aged 21) refers to as "the olden days", where traditional structures were untouched by modernity, or the participants spoke about modernity as improving various aspects of their daily lives. The participants alluded to the contested process whereby non-medical issues are seen to have become medicalised, for example child-birth, death, weight-loss, and TMC, which are now commonly done in clinical settings (Conrad, 2013). Additionally, something as common as travel requires that individuals produce inoculation certificates for inspection by immigration officials (such as yellow fever) should they be visiting an area where there is a high risk of disease contraction. It is primarily contested because it implies that some experiences can reside in the medical domain and others cannot (Ballard \& Elston, 2005). According to Morgan (1998), for medicalised modernity to firmly appropriate otherwise "non-medical" practices, the conceptualisation of the object to be medicalised requires the development of theories and paradigms.

With modernity, there has been a strong focus on the relevance of medicine in improving the everyday lives of people (since it generally increases longevity and overall well-being). For example, P13 (married, isiZulu-speaking, aged 49) considers the introduction of medicalised modernity as preventing critical injuries and deaths of young initiates who are going through the traditional rite of passage into adulthood as TMCs are sometimes performed under medical conditions. He reflects on how "things are much better now".

During modernisation there is increasing focus upon medicine within capitalism, urbanisation, globalisation, industrialisation, secularisation and rationalisation (Larouche \& Potvin, 2013). Regardless of the individual participants' position regarding tradition or modernity, almost all the participants noted that the advent of HIV has compelled them to consider medical interventions that do not neatly adhere to their traditional practices and customs. As such, the key example of medicalised modernity for this paper is the 
medicalisation of TMC, but also VMAMC for HIV prevention, in ways that are seemingly contradictory in meaning to those ascribed to the traditional African rite of passage. These contradictions represent the site of tension between medical modernity and traditional practices, which is underpinned by the following theoretical categories.

\section{Embracing modernity}

The participants referred to how South Africa, through urbanisation, has become increasing modernised to embrace medicine and how citizens would generally approve of medical public health interventions in consideration of the HIV pandemic. For example, as a student doctor in his final year of study, P29 (single, English-speaking, aged 24) says that "[...] people are scared of HIV and if you tell someone that this [VMAMC] can decrease your chances of getting HIV, I think it will probably be quite a successful programme. I think, I think people will react positively to it".

The legitimisation of medical modernity is substantiated by the fact that it seems to occur at a number of ecological levels. For example, traditionally non-medicalised practices are medicalised at the macro-level through institutionalisation. This relies on a systematic alliance between various disciplines. It emerged from the data that the medicalisation of TMC or VMAMC for HIV prevention becomes legitimised through buy-in from the legal system, private and public medical aids, pharmaceuticals, academic hospitals, nongovernment organisations (NGOs), and the national department of health $(\mathrm{NDoH})$. Thus institutionalisation compels citizens to acknowledge the authority of medical understandings of the male body and how it requires modification in order to prevent HIV infection.

"[...] they [South Africans] will agree [with VMAMC] because the methods that are used at the hospital are $99.9 \%$ accurate in terms of preventing HIV and AIDS. There is no other African who wants to contribute to the population infected. We must use every alternative that we have medically to fight HIV." (P7 - single, isiXhosa-speaking, aged 18)

"Preventing HIV it is our main goal and we are trying by all means to make sure to keep the numbers minimum and which is kind of difficult. We try to incorporate as many things as possible but it is not going to make everything better it has to be a process in which people learn and know that what this is all about and know that percentage it is not that high of them reducing their chances of getting infected." (P10 - single, SiSwati-speaking, aged 19)

While some participants indicated that there can be no doubt that tradition often overrides medical justifications for VMAMC, other participants considered medicine to 
be the most highly regarded and significant form of knowledge required in addressing the HIV pandemic. From this perspective, medical bodies become dominant as they are permitted to retain or reject traditional paradigms of male circumcision, and in so doing, traditional values and customs become medically appropriated. Proponents of modernity claim that maintaining tradition without critically reviewing its purpose, social value, consequences and outcomes, is detrimental to society's development (Dirlik, 2003). Thus, modernity leaves little space for traditional beliefs or customs as rationalism, critical thought, urbanisation and industrialisation take hold. Therefore, it is not surprising that the participants elided medical male circumcision (MMC) with traditional practices, for example ritualised genital cutting and penile modifications.

"I agree that circumcision is important, but it needs medical intervention. The way it was done before, it was traditional without consulting the western way of life. Now, for us to save lives, we need to involve the western-trained people: doctors, nurses, especially those, so importantly so, all those who have gone through the same process. So take the same people that are qualified, who have done the traditional way, to be the one assisting there, and then it will improve the life of the humankind in South Africa." (P27 - single, isiXhosa-speaking, aged 42, student doctor in his final year of study)

Similarly P13 (married, isiZulu-speaking, aged 49) speaks to the medicalisation of TMC by saying that "[...] circumcision done at hospital is safer than the one done at initiation schools [...] there it is cold, unhygienic and they use the same instruments for every young men and also the traditional medicine that is given to them it's not safe some of them."

Participants considered the gap between tradition and medicalised modernity as shrinking:

"I do know that traditional healers in Limpopo, Mpumalanga areas are becoming more and more involved with the medical community. I know there is a traditional healers' association that is formed that considers itself to be just another arm of medicine and the idea is that traditional healers should have his place and a medical doctor have his place and they should be able to work together that is the idea. There is still a lot of animosity between the two groups of people obviously but it's getting there. I do think it can be brought in." (P29 - single, English-speaking, aged 24, student doctor in his final year of study)

"Most people still believe in their culture, it would be much wiser if we could try teaching those traditional surgeons and those who take care of the boys at 
initiation school, if the modern medicine coming together with traditional medicine trying to increase the knowledge they have to deal with such issues." (P10 - single, SiSwati-speaking, aged 19)

The participants often referred to "western medicine" when they spoke to MMC. The tension between medicalised modernity and traditional practices may thus reside in the understanding that medicine is a "western" concept, which (for at least some participants) implies non-African or anti-African. For example, P1 (single, isiZulu-speaking, aged 18) refers to MMC as being "the western way". P2 (single, isiZulu-speaking, aged 18) says that, "the Western community just realised the importance of circumcision so Africans had already been circumcising from long time ago". Modernity is often regarded as being part of westernisation, as a number of western institutions (such as modern medicine) are introduced to "traditional" societies, where the adoption thereof either does not make sense in the existing culture or is viewed with general suspicion and fear.

\section{Corrosion of tradition}

The participants indicated that some members of the South African public may reject any medical HIV prevention strategy because of the perception that western medicine has attempted to corrode African traditions. P1 (single, isiZulu-speaking, aged 18) says, "Actually I can't say that I support it [VMAMC] because I've never seen any written evidence that says that male circumcision can prevent the risk of getting HIV." This statement indicates that the public may require further proof and evidence that supports public health claims of VMAMC preventing HIV before they may consider the uptake thereof. However, given the longstanding historical significance of TMC, men seem satisfied to rely on anecdotal evidence from their communities, families, and peers regarding the value of maintaining such traditional practices.

P26 (single, English-speaking, aged 23, student doctor in his final year of study) says, "I think it [VMAMC] is going to be received with mixed feelings. And also, I think the cultural differences are also going to play an important role, you know. Some groups will readily welcome it. Some ... not so much." P7 (single, isiXhosa-speaking, aged 18) also indicates that, "I think they [other South Africans] will feel that their religions and traditions are brought down. I mean these methods they have been using it for ages and the medicine has developed in a rapid way." Public health practitioners may need to bear this in mind as they introduce a novel HIV intervention to a public that holds time-honoured meanings of TMC (or non-circumcision), which VMAMC seems to contest. For example, P25 (single, SiSwati-speaking, aged 22) says that people from traditionally circumcising backgrounds would make meaning of VMAMC for the purposes of HIV prevention as an intervention designed to further compromise the significance of their traditional practices: 
"[...] the moment any medical connotation is attached to it [male circumcision], it loses its intensity and its value [...] the people who actually do it, they are old fashioned [...] once they hear something that has to do with medicine, they just automatically switch off and they are not interested."

"In the olden days, all the religions used to practise male circumcision [...] In the Old Testament, if you were not circumcised, you were not allowed in heaven but in the New Testament all that changed. Some people will only want to have circumcision done for religious reasons and will never want that reason to change." (P10 - single, SiSwatispeaking, aged 19)

TMC remains discordant within dominant western traditions (such as medicalised modernity), even for those that embrace male circumcision in its medicalised form. Participants reflected on medicalised modernity within tradition:

"I suspect that people are still quite traditional and... they won't... I don't know, I suppose it's a toss-up between the tradionality [sic], not wanting to turn circumcision into a medical procedure as opposed to a traditional procedure." (P29 - single, English-speaking, aged 24, student doctor in his final year of study)

Medicalised modernity in the health sector is regarded as the transitioning of societies from "traditional" views of health and illness to "modern" perspectives. It has been argued that medicalised modernity is not simply the introduction of "western" medical practices at the expense of, for example, African traditions (Pratt, 2012). However, socio-political events such as colonisation and Apartheid with its legacy in South Africa were driven by western ideologies that compromised African traditions, identity, independence and autonomy (Baronov, 2010). Thus, while modernisation theorists claim that medicalised modernity is erroneously conflated with westernisation, colonialists did in fact seek to westernise African tribes.

This may also explain why, despite VMAMC and medicalised TMC posing fewer health risks than TMC, some participants insisted that having the ritual performed under medical conditions (as opposed to in rural initiation schools by untrained traditional healers) would impinge on the traditional value of the rite, and therefore, were opposed to the implementation of VMAMC (Mayatula \& Mavundla, 1997; Meissner \& Buso, 2007; Mavundla et al, 2009). Ballard and Elston (2005) noted that while medicine's jurisdiction has extended itself beyond the realm of health and disease by intruding on society, the public (as healthcare consumers) can either embrace or resist the medicalisation of society. For those who oppose the medicalisation of traditional rites, VMAMC means the corrosion of tradition. 
A number of studies have found that medical interventions have been resisted on traditional grounds despite their benefits to the public (Chatters, 2000; McKinlay \& Marceau, 2000; Jackson \& Scambler, 2007). Such interventions may include the amputation of an infected organ or body part, repudiation of organ donation, or refusing to perform an autopsy on the deceased, all of which are related to religious and cultural beliefs that the body must remain intact for the after-life, as well as the refusal of blood transfusions or organ transplants due to the belief that the "soul" resides in the living tissue and fluids of the body. Thus, belief-systems play a role in HIV prophylactic VMAMC meaning-making, and will need to be considered should South Africa remain committed to the up scaling of this public health intervention as part of the UNAIDS agenda for HIV prevention (UNAIDS, 2013).

As such, if VMAMC is regarded as a challenge to the belief systems of particular religious and/or cultural groups within the South African population, public health practitioners may need to be aware that such groups may resist the uptake of VMAMC as a HIV prevention intervention.

\section{Resisting medical modernity}

In an effort to counter the impact of medicalised modernity on tradition, some participants indicated that their sons would have no choice but to adhere to the participants' traditional practices regarding TMC and TMI:

"My son will go through the cultural way it's not only initiations; there are so many things that are taught to the person to make him into a young man. So he'll [my son] have to go [be circumcised] that way. But cultural way must be improved upon by involving qualified people to assist. But cultural way is the best. Not the hospital way." (P27 - single, isiXhosa-speaking, aged 42, student doctor in his final year of study)

This statement shows the tension between medicalised modernity and traditional practices for P27 since he so strongly advocates for the medicalisation of TMC (as well as VMAMC for HIV prevention); however, he will insist that his son continue the practice of his traditional customs, which seems to carry a different (weighted) meaning to disease prevention (in the form of VMAMC).

South African efforts (particularly in the Eastern Cape where the majority of TMCs are performed) to integrate VMAMC with TMC, such as introducing the Tara Klamp (a VMAMC instrument that significantly reduces the risk of penile amputation) into the ritual of TMC, have been largely unsuccessful due to the lack of support for its utilisation by traditional leaders (Peltzer \& Kanta, 2009; Kepe, 2010). 
In fact, participants considered the recent increase in botched TMCs as being a sign of medicalised modernity:

"This [botched TMCs] did not happen during the time of our ancestors because the person, who used to perform the procedure, cutting of foreskin, was trained and also experienced. I have heard that about 15 to 30 boys had to have their penises amputated." (P15 - married, SeSotho-speaking, aged 52)

On the other hand, participants considered the medicalisation of tradition was connoted as a sign of modernity and the organic progression of society.

"I think it's just an indication that society has moved from doing things the olden way you see in the olden days the community used to have a person who specialised in circumcision. There were no incidences where there were these bad circumcisions and stuff like that." (P2 - single, isiZulu-speaking, aged 18)

P4 (single, isiZulu-speaking, aged 18) believes that modifications to the body should be medicalised: "I think they [TMC practices] should stop. Those circumcising at the mountains ... they should support circumcision that is performed at the hospital, because it is safer."

However, participants did reflect on the differences in willingness to embrace VMAMC for HIV prevention over TMC for people who are from urban areas of the country and those from rural areas, indicating that urbanisation played a feature role in the tension between medical modernity and traditional practices.

\section{Urbanisation}

Modernity was alluded to in the interview data as participants considered the urbanisation of various parts of the country. Here participants reflected on how modernity has widened the tradition-modern gap between people residing in rural and urban areas of South Africa. For example:

"It's all about culture and where you are located for instance if you grew up in townships and you know that your father did not go for circumcision, you will not go either. In some culture some do it and some don't. For example, us moshweshwes [SeSotho men], we don't do it because we grew up in townships." (P16 - single, SeSotho-speaking, aged 31)

"I think again it's going to be different whether you're in an urban environment or rural environment. Rural environments tend to be more traditional and traditional 
reasons would be stronger than the medical ones but in a city like Johannesburg where everything is like cosmopolitan a lot of people are losing their traditions." (P29 - single, English-speaking, aged 24, student doctor in his final year of study)

Here P29 highlights that during urbanisation, tradition seems to recede to make way for medicalised modernity. He went on to say that traditional structures have already buckled under the strain of medicalised modernity, and that the reasons underpinning male circumcision in South Africa will primarily be medical "as long as its offered widely enough and advertised widely enough, then I think it [VMAMC] will catch up [to TMC in popularity], it [VMAMC] will work." Participants addressed the "inevitability" of medicalised modernity filtering into traditional practices:

"Yes, you see when it [TMC] was done, I was young, and I was a rural boy. I've learnt through the traditional way. But now that I'm medically orientated knowing matters of hygiene will need to be improved, that's number one. [...] it must be done by a qualified person, because in the past, yes we have qualified people, traditionally, but you know they cannot produce anything that is a certificate or otherwise. But if it's [medicalised TMC] done by a medical doctor, there's always recourse for a person that could be have been harmed in the process. If a person has been harmed in the process [of medicalised TMC], he can always know that he can go the legal route and the doctor can be sued and he'd [the doctor] have to pay. But, the way it [TMC] was done previously, it was that there was no guaranteed security that if someone has done it wrongly. Especially now that in our time, we see so many people that have lost their penises because of the old way of doing things." (P27 - single, isiXhosa-speaking, aged 42, student doctor in his final year of study)

Thus, not only did participants regard medical modernity and urbanisation as an organic progression of societies away from traditional structures and practices, they also considered the medicalisation of tradition favourably. Participants referred to the reports of botched traditional circumcisions as they considered state regulation of traditional practices through medicalised modernity. For example, P2 (single, isiZulu-speaking, aged 18) says that as a result of the increased number of botched TMCs, "government needs to take better control of this whole thing and start instituting safe and more hygienic ways of circumcision."

"I also believe that culturally is the best but [...] it needs to be improved because of the hygiene. There is no hygiene at all and [...] one is not supposed to drink water for a certain period of time, that's dehydration. Now that I am clear of such things I don't think it's the right thing [...] So, that's why I am saying if ever they might involve the department of health on the circumcision while it's being done culturally, but they

PINS [Psychology in Society] 52 • 2016|34 
must also involve the department of health." (P28 - single, isiXhosa-speaking, aged 35 , student doctor in his final year of study)

However, the role of the state in regulating medicalised TMC or promoting HIV prophylactic VMAMC was also regarded with suspicion as participants feared that this public health HIV prevention intervention may simply be up scaled in an effort to wield socio-political control of its citizens.

\section{Medical modernity as socio-political control}

Historically, public health has been met with suspicion and mistrust (Durant et al, 2011; Elder et al, 2012; Yassi et al, 2014) as it might be perceived as fulfilling the state's agenda for population health over the personal liberties and autonomy of the individual. Participants, regardless of their views of TMC or VMAMC, felt that the state should be involved (to varying degrees) to regulate the practice. For example, P20 (single, isizuluspeaking, aged 34) believed that "[...] at initiation school there should be someone to supervise the procedure to ensure safety since people insist on doing male circumcision at initiation school."

"Government should be involved 100\% in male circumcision and the teaching of inkatha [Zulu men] and ingcibi [traditional man who performs TMC], the people that are responsible for the surgery itself in the bush. Those guys need to be educated thoroughly. The ways of living in the bush is not appropriate, we have to teach those guys how to do the things to avoid infections because the only thing that is killing people there is infection. Control infection nothing else." (P28 - single, isiXhosa-speaking, aged 35, student doctor in his final year of study)

Here P28, in training to be a medical professional, believes that the state should regulate the practice of TMC to ensure that traditional healers are adequately trained to perform such circumcisions under sterile conditions to prevent infection yet does not believe that the rite should be medicalised or that the state should play any further structural role in the practice of TMI and TMC. Similarly, P25 (single, SiSwati-speaking, aged 22) thinks:

"[...] a certain level control is necessary because if you look at the traditional healers they also have governing body now because of various crimes they can commit. It is necessary to get cultural circumcision managed but not as hands-on as government normally does."

P25 goes on to say that:

"[... the] government have their interests, political interests and those political interests 
have certain attachments to certain socio-economic happenings within a country. So for country's economy to grow they will need certain social stability. The government have their own alterative motive for having this circumcision done. So government has an agenda that extends beyond caring for that individual."

Similarly, P22 (married, isiZulu-speaking, aged 64) worries that government policies regarding VMAMC may only be developed to serve the cultural agenda of the president: "[...] if it is according to the government, it [VMAMC] will not work because look the previous president was Xhosa and now Zuma is Zulu so it means that every president will implement laws according to his culture". Such views link the HIV prevention agenda with that of the state.

Participants' views that the state was attempting to control its citizens in the face of the HIV pandemic highlight a stark contrast between the current government administrations (under President Jacob Zuma) as compared with the Mbeki administration, where the latter regime was criticised worldwide for its denialism stance on the link between HIV and AIDS, the banning of ART distribution in state hospitals, as well as an overall delayed response to the HIV pandemic in South Africa (Kalichman, 2014). Furthermore, participants referred to the traditional background of the country's president as they considered VMAMC as being a form of socio-political control. President Zuma is a Zulu man and thus comes from a non-circumcising tradition, yet he has publically stated that he endorses the implementation of this medical intervention and has encouraged all adult men to undergo VMAMC for HIV prevention. Participants believed that should future elected presidents belong to traditionally circumcising cultures or religions, they are likely to withdraw such endorsements for HIV-preventative VMAMC in favour of traditional (potentially nonmedicalised) male circumcision practices. This means that many participants regarded the apparent objectivity of proposed VMAMC with suspicion.

Therefore, VMAMC was understood as being an intervention that would be implemented to comply with the personal agenda of the presidency rather than as a HIV prevention strategy that is in the best interests of the populace. However, the medicalisation of TMC and HIV prophylactic VMAMC speak to a movement away from TMC practices in contemporary times. Medicalised modernity then generated a sense of tension for those who were expected to maintain traditional customs related to male circumcision, since it was seen as challenging traditional structures.

Participants suggest that the increased media attention on botched traditional circumcisions at initiation schools may be part of a government-conspiracy in order to increase its position of socio-political control: 
"I was actually thinking because of the publicity about the botched circumcisions. It was actually a belief of mine that the government is trying to intercept the whole thing and trying to get control over it and manage it as their own type of thing and regulate it." (P25 - single, SiSwati-speaking, aged 22)

P25 goes on to reflect on this further: "[...] the thing with the government, they will tend to want to control and manage the situation". TMC has a long history of being state-controlled and medically appropriated. For example, in the 1890s English physicians recommended that the Jewish rite be performed under clinical surgical conditions by neonatal surgeons (Carpenter, 2010). According to Gollagher (2000), these physicians considered Jewish circumcisions to be archaic, dirty and unsafe. At the same time, these physicians asserted that being uncircumcised was associated with masturbation and psychological (as well as physical and mental) disorders such as insanity, neurosis, pubescent turmoil, female sexual aloofness, epilepsy, nymphomania, blindness, hair growth on the palms of the hands and soles of the feet, as well as the diagnosis of hysteria (Darby, 2003; Hodges, 2005; Aggleton, 2007).

They believed that intact males found masturbation more pleasurable and thus may be more prone to self-stimulation. By severing a sensitive portion of the penis, many exponents of MMC argued that young boys' hands would not be tempted into masturbatory pleasures (Darby, 2003; Alouf, 2005). Young English boys were, therefore, medically circumcised during the late 1800 s as a prophylaxis to masturbation. This practice was maintained into the early 1900s, with the Royal College of Surgeons endorsing MMC in pamphlets, On circumcision as preventative of masturbation (1891), and Circumcision, its advantages and how to perform it (1893). During this time, many have argued that male circumcision was medicalised so as to regulate sexuality and morality.

Participants considered the political ramifications of allowing the state to perpetuate the notion of the naturally defective male body. This is complemented by the understanding of male circumcision, and VMAMC, as a denaturalisation of the male body. P22 (married, isiZulu-speaking, aged 64) asks: "[...] if God created you this way why should you remove a part of your body?".

"The government doesn't have the right to tell people to do something to their bodies because some people regard their bodies as temple created by God. So to them the way God made them is the way they are going to stay. Then if you start telling them to cut a piece of their body they will ask question then saying that why were they created like that." (P10 - single, SiSwati-speaking, aged 19) 
As with numerous other public health interventions, the Straussian grounded theory analysis showed that participants feared that a formal institutionalisation of male circumcision could witness the male body (understood as being inherently defective and pathological) being used as a leverage site for globalisation. Participants referred to a growing risk that there could be an increase in social and political control masquerading as the preservation of health (Zola, 1979; Morgan, 1998). The severity of the HIV pandemic in South Africa legitimises interpreting traditional practices through a medical lens. Zola (1975) claimed that as citizens subscribe to this perspective by medicalising TMC and advocating VMAMC for HIV prevention, they knowingly or unknowingly promote the utilisation of medical science for the purposes of socialpolitical control. This is possible because the state (through the public health system) is able to cloak itself with technical impartiality and benevolent scientific processes, resulting in a more enthusiastic and "rational" public acceptance of this medical practice of permanent genital modification (Zola, 1975).

\section{Conclusion}

The inclusion of VMAMC in South Africa as part of a comprehensive HIV prevention intervention has created a unique space for empirical investigation into the tension that exists between tradition and modernity and the impact that this has on population health. The tension that emerges from this has an effect on the post-traditional order whereby one, particularly those from urban populations, can embrace tradition as well as medicalised modernity, since they are not seen to be mutually exclusive. Thus, as much as participants regard themselves as being either traditional or modern, this paper showed that this binary conceptualisation is often blurred in practice. With regards to this study, participants seemed to initially locate VMAMC for HIV prevention within the meanings that they assigned to TMC. Depending on whether or not meanings of TMC were aligned with the meanings of VMAMC, individuals then reconsidered their meanings of TMC in relation to the severity of the HIV pandemic. If they were unable to resolve or reconsider the meanings that they had assigned to TMC, a tension between medical modernity and traditional practices persisted. The resolution or indetermination of this tension has implications for the up scaling of VMAMC as a HIV intervention and should be considered by public health practitioners.

Acknowledgement. I wish to acknowledge Professor Brett Bowman as the supervisor of the broader study upon which this paper is based.

\section{References}

Aggleton, P (2007) “Just a snip?”: A social history of male circumcision. Reproductive Health Matters, 15(29), 15-21. 
Alouf, B (2005) What your doctor may not tell you about circumcision: Untold facts on America's most widely performed \& most unnecessary-surgery. Journal of the National Medical Association, 97(6), 850-852.

Auvert, B, Taljaard, D, Lagarde, E, Sobngwi-Tambekou, J, Sitta, R \& Puren, A (2005) Randomized, controlled intervention trial of male circumcision for reduction of HIV infection risk: The ANRS 1265 Trial. Public Library of Science, 2(11), 298-308.

Auvert, B, Taljaard, D, Rech, D, Lissouba, P, Singh, B, Bouscaillou, J, \& Lewis, D (2013) Association of the ANRS-12126 male circumcision project with HIV levels among men in a South African township: Evaluation of effectiveness using cross-sectional surveys. PLoS Medicine, 10(9), e1001509.

Babones, S J \& Babcicky, P (2010) The globalization challenge to population health. International Review of Modern Sociology, 36(2), 101-120.

Bailey, R C, Plummer, F A \& Moses, S (2001) Male circumcision \& HIV prevention: Current knowledge \& future research directions. The Lancet Infectious Diseases, 1, 223-231.

Ballard, K \& Elston, M A (2005) Medicalisation: A multi-dimensional concept. Social Theory \& Health, 3, 228-241.

Baronov, D (2010) The African transformation of Western medicine and the dynamics of global cultural exchange. Philadelphia: Temple University Press (2010).

Bhattacharjee, P K (2008) Male circumcision: An overview. African Journal of Paediatric Surgery, 5(1), 32-36.

Boddy, B (1989) Wombs \& alien spirits: Women, men, \& the Zar cult in northern Sudan. London: Zed Books.

Bonner, K (2001) Male circumcision as an HIV control strategy: Not a "natural condom". Reproductive Health Matters, 9, 143-155.

Boyle, G J \& Hill, G (2011) Sub-Saharan African randomised clinical trials into male circumcision and HIV transmission: Methodological, ethical and legal concerns. Journal of Law \& Medicine, 19(2), 316-334.

Carpenter, L M (2010) On re-medicalisation: Male circumcision in the United States and Great Britain. Sociology of Health \& Illness, 32(4), 613-630.

Charmaz, K (2014) Constructing Grounded Theory. Thousand Oaks: Sage Publications.

Chatters, L M (2000) Religion and health: Public health research and practice. Annual Review of Public Health, 21(1), 335-367. 
Conrad, P (2013) Medicalisation: Changing contours, characteristics, and contexts, in Cockerham, WC (ed) (2013) Medical Sociology on the move. Heidelberg: Springer.

Crowley, I P \& Kesner, K M (1990) Ritual circumcision (Umkhwetha) amongst the Xhosa of the Ciskei. British Journal of Urology, 66(3), 318-321.

Darby, R L (2003) The Masturbation Taboo \& the rise of routine male circumcision: A review of the historiography. Journal of Social History, 36(3), 737-757.

De Vincenzi, I \& Mertens, T (1994) Male circumcision: A role in HIV prevention?

AIDS, 8, 153-160.

Department of Health (2013) National Strategic Plan for HIV and AIDS/

Comprehensive HIV and AIDS Treatment Plan Statistics Memorandum. Pretoria:

Department of Health (2013).

Dirlik, A (2003) Global modernity? Modernity in an age of global capitalism. European Journal of Social Theory, 6(3), 275-292.

Dowsett, G W \& Couch, M (2007) Male circumcision and HIV prevention: Is there really enough of the right kind of evidence? Reproductive Health Matters, 15(29), 33-44.

Durant, R W, Legedza, A T, Marcantonio, E R, Freeman, M B, \& Landon, B E (2011)

Different types of distrust in clinical research among whites and African Americans. Journal of the National Medical Association, 103(2), 123-130.

El-Hout, Y \& Khauli, R B (2007) The case for routine circumcision. Journal of Men's Health \& Gender, 4(3), 300-305.

Elder, K, Ramamonjiarivelo, Z, Wiltshire, J, Piper, C, Horn, W S, Gilbert, K L, \& Allison, $\mathrm{J}$ (2012) Trust, medication adherence, and hypertension control in Southern African American men. American Journal of Public Health, 102(12), 2242-2245.

Faist, T (2000) Transnationalization in international migration: implications for the study of citizenship and culture. Ethnic \& Racial Studies, 23(2), 189-222.

Gollagher, D L (2000) Circumcision: A history of the world's most controversial surgery. New York: Basic Books.

Green, L W, McAllister, R G, Peterson, K W \& Travis, J W (2008) Male circumcision is not the HIV "vaccine" we have been waiting for! Future, 2(3), 193-199.

Halperin, D T \& Bailey, R C (1999) Male circumcision \& HIV infection: 10 years and counting. The Lancet Infectious Diseases, 354, 1813-1815.

Hodges, F M (2005) History of sexual medicine: The anti-masturbation crusade in antebellum American medicine. The Journal of Sexual Medicine, 2(5), 722-731. 
Howard-Payne, L (2016) Glaser or Strauss? Considerations for selecting a grounded theory study. South African Journal of Psychology. doi:10.1177/0081246315593071.

Howard-Payne, L \& Bowman, B (2016). Fathers' expectations of traditional male initiation for their sons: Implications for the uptake of HIV prophylactic voluntary medical adult male circumcision, in Makiwane, M, Nduna, M, \& Khalema, N E (eds) (2016) Children in South African families: Lives and times. London: Cambridge Scholars Publishing.

Howard-Payne, L (2015) The methodological implications of relying upon fieldworkers for qualitative health psychology research. Forum: Qualitative Social Research, 16(2), Art. 3, http://nbn-resolving.de/urn:nbn:de:0114-fqs150239

Jackson, S \& Scambler, G (2007) Perceptions of evidence-based medicine: Traditional acupuncturists in the UK and resistance to biomedical modes of evaluation. Sociology of Health \& Illness, 29(3), 412-429.

Kalichman, S C (2014) The psychology of AIDS denialism: Pseudoscience, conspiracy thinking, and medical mistrust. European Psychologist, 19(1), 13-22.

Kepe, T (2010) "Secrets" that kill: Crisis, custodianship and responsibility in ritual male circumcision in the Eastern Cape Province, South Africa. Social Science \& Medicine, 70(5), 729-735.

Langa, M (2010) Contested multiple voices of young masculinities amongst adolescent boys in Alexandra Township, South Africa. Journal of Child and Adolescent Mental Health, 22(1), 1-13.

Larouche, A \& Potvin, L (2013) Stimulating innovative research in health promotion. Global Health Promotion, 20(2), 64-69.

McKinlay, J B \& Marceau, L D (2000) To boldly go .... American Journal of Public Health, 90(1), 25-33.

Mark, D, Middelkoop, K, Black, S, Roux, S, Fleurs, L, Wood, R \& Bekker, L (2012) Low acceptability of medical male circumcision as an HIV/AIDS prevention intervention within a South African community that practises traditional circumcision. South African Medical Journal, 102(6), 571-573.

Massry, S G (2011) History of circumcision: A religious obligation or a medical necessity. Journal of Nephrology, 24(17), S100-S102.

Mavundla, T R, Netswera, F G, Bottoman, B \& Toth, F (2009) Rationalization of indigenous male circumcision as a sacred religious custom health beliefs of Xhosa men in South Africa. Journal of Transcultural Nursing, 20(4), 395-404. 
Mayatula, V \& Mavundla, T R (1997) A review on male circumcision procedures among South African blacks. Curationis, 20(3), 16-20.

Mbito, M N \& Malia, J A (2008) Transfer of the Kenyan Kikuyu male circumcision ritual to future generations living in the United States. Journal of Adolescence, 32, 39-53.

Meissner, O \& Buso, D L (2007) Traditional male circumcision in the Eastern Cape -scourge or blessing? South African Medical Journal, 97(5), 371-374.

Morgan, K P (1998) Contested bodies, contested knowledges: Women, health, \& the politics of medicalisation applied to circumcision, in Sherwin, S (ed) (1998) The politics of women's health: Exploring agency and autonomy. Philadelphia: Temple University Press.

Morris, B J, Bailey, R C, Klausner, J D, Leibowitz, A, Wamai, R G, Waskett, J H, \& Hankins, CA (2012) Review: A critical evaluation of arguments opposing male circumcision for HIV prevention in developed countries. AIDS Care, 24(12), 1565-1575.

Moses, S, Bailey, R C \& Ronald, A R (1998) Male circumcision: Assessment of health benefits \& risks. Sexually Transmitted Infections, 74(5), 368-373.

Nafstad, H E, Blakar, R M, Botchway, A, Bruer, E S, Filkukova, P \& Rand-Hendriksen, $\mathrm{K}$ (2013) Communal values and individualism in our era of globalization:

A comparative longitudinal study of three different societies, in Knoop, H H \& Fave, A D (eds) (2013) Well-Being and cultures: Perspectives from Positive Psychology. Heidelberg: Springer.

Peltzer, K \& Kanta, X (2009) Medical circumcision and manhood initiation rituals in the Eastern Cape, South Africa: A post intervention evaluation. Culture, Health \& Sexuality, 11(1), 83-97.

Pratt, M L (2012) Modernity andpPeriphery: Toward a global and relational analysis, in Mudimbe-Boyi, E (ed) (2012) Beyond dichotomies: Histories, identities, cultures, and the challenge of globalization. Albany: SUNY Press.

Schifirneţ, C (2012) Tendential modernity. Social Science Information, 51(1), 22-51.

Schoen, EJ (2007) Circumcision as a lifetime vaccination with many benefits. Journal of Men's Health and Gender, 4(3), 306-311.

Siegfried, N, Muller, M, Volmink, J, Deeks, J J, Egger, M, Low, N N, \& Williamson, P R (2003) Male circumcision for prevention of heterosexual acquisition of HIV in men.

Cochrane Database Systematic Review, 3, doi:10.1002/14651858.CD003362.

Silverman, E K (2004) Anthropology \& circumcision. Annual Review Anthropology, 33, 419-445. 
Stine, GJ (2008) AIDS Update 2008. New York: McGraw-Hill.

Tierney, W G (2014) Danny's fight for life cultural flexibility and life history method reexamined. Qualitative Inquiry, 20(1), 95-107.

UNAIDS (2013) Global Report: UNAIDS report on the global AIDS epidemic 2013. Joint United Nations Programme on HIV/AIDS. Date accessed: 22 December 2013: http://www. unaids.org/en/media/unaids/contentassets/documents/epidemiology/2013/gr2013/ UNAIDS_Global_Report_2013_en.pdf

UNAIDS/WHO (2013) Guidelines for second generation HIV surveillance: An update: Know your epidemic. Date accessed: 22 December 2013: http://www.who.int/iris/ bitstream/10665/85511/1/9789241505826 eng.pdf

Van Howe, R S (1999) Circumcision \& HIV infection: Review of the literature \& metaanalysis. International Journal of Sexually Transmitted Diseases \& AIDS, 10, 8-16.

Van Howe, R S, Cold, C J \& Storms, M R (2000) Male circumcision \& HIV prevention: Some science would not have gone amiss. British Medical Journal, 321, 1467-1468.

Van Howe, R S \& Storms, M R (2011) How the circumcision solution in Africa will increase HIV infections. Journal of Public Health in Africa, 2(1), 11-15.

Vaughan, L \& Arbaci, S (2011) The challenges of understanding urban segregation. Built Environment, 37(2), 128-138.

Ward, C (2013) Probing identity, integration and adaptation: Big questions, little answers. International Journal of Intercultural Relations, 37(4), 391-404.

Westercamp, N \& Bailey, R C (2007) Acceptability of male circumcision for prevention of HIV \& AIDS in Sub-Saharan Africa: A review. AIDS Behaviour, 11(3), 341-355.

Williams, B G, Lloyd-Smith, J O, Gouws, E, Hankins, C, Getz, W M, Hargrove, J, \& Auvert, B (2006) The potential impact of male circumcision on HIV in Sub-Saharan Africa. PLoS Medicine, 3(7), 1032-1040.

Yassi, A, O’Hara, L M, Engelbrecht, M C, Uebel, K, Nophale, L E, Bryce, E A, \& Spiegel, J M (2014) Considerations for preparing a randomized population health intervention trial: Lessons from a South African-Canadian partnership to improve the health of health workers. Global Health Action, 7, doi:10.3402/gha.v7.23594.

Zola, I K (1975) In the name of health \& illness: On some socio-political consequences of medical influence. Social Science \& Medicine, 9, 83-87.

Zola, I K (1979) Pathways to the doctor - from person to patient. Social Science \& Medicine, 9, 83-87. 